\title{
Rehab facilities face COVID-19 crunch as more patients recover
}

\author{
— Cite as: CMAJ 2020 June 29;192:E732-3. doi: 10.1503/cmaj.1095878
}

Posted on cmajnews.com on June 12, 2020

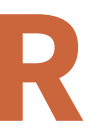

ehabilitation centres have undergone dramatic transformations over the past three months to accommodate patients recovering from coronavirus disease 2019 (COVID-19). An estimated 1 in 20 patients with COVID-19 requires critical care during their illness and is likely to need extensive physical and pulmonary rehabilitation after the fact.

Rehab facilities have urgently increased their capacity, recognizing that many patients with COVID-19 may suffer serious problems long after they recover. They've partitioned beds for patients with active infections, secured extra personal protective equipment, paused in-person outpatient visits, and launched virtual rehab programs.

"Sometimes people think they get off a ventilator, they're discharged from the intensive care unit, and then they go home. But it's not that simple," says Dr. Marla Beauchamp, an assistant professor in McMaster University's physiotherapy program. "They probably can't walk. They probably can't stand up on their own. It will take a long time for these patients to get back to their baseline levels."

Existing rehab programs may also need to be modified for patients with CoVID-19. According to Dr. Chris Grant, a rehab specialist at Foothills Medical Centre in Calgary, rehab systems typically aren't "well-geared" to care for an influx of patients with lung injuries. "Formal rehab has focused traditionally on brain injury, spinal cord injury, amputation, and a few other conditions. Big lung injuries usually aren't on that list," Grant says.

Patients recovering from COVID-19 will likely need individualized exercise programs to regain muscle strength and fitness after hospitalization, combined

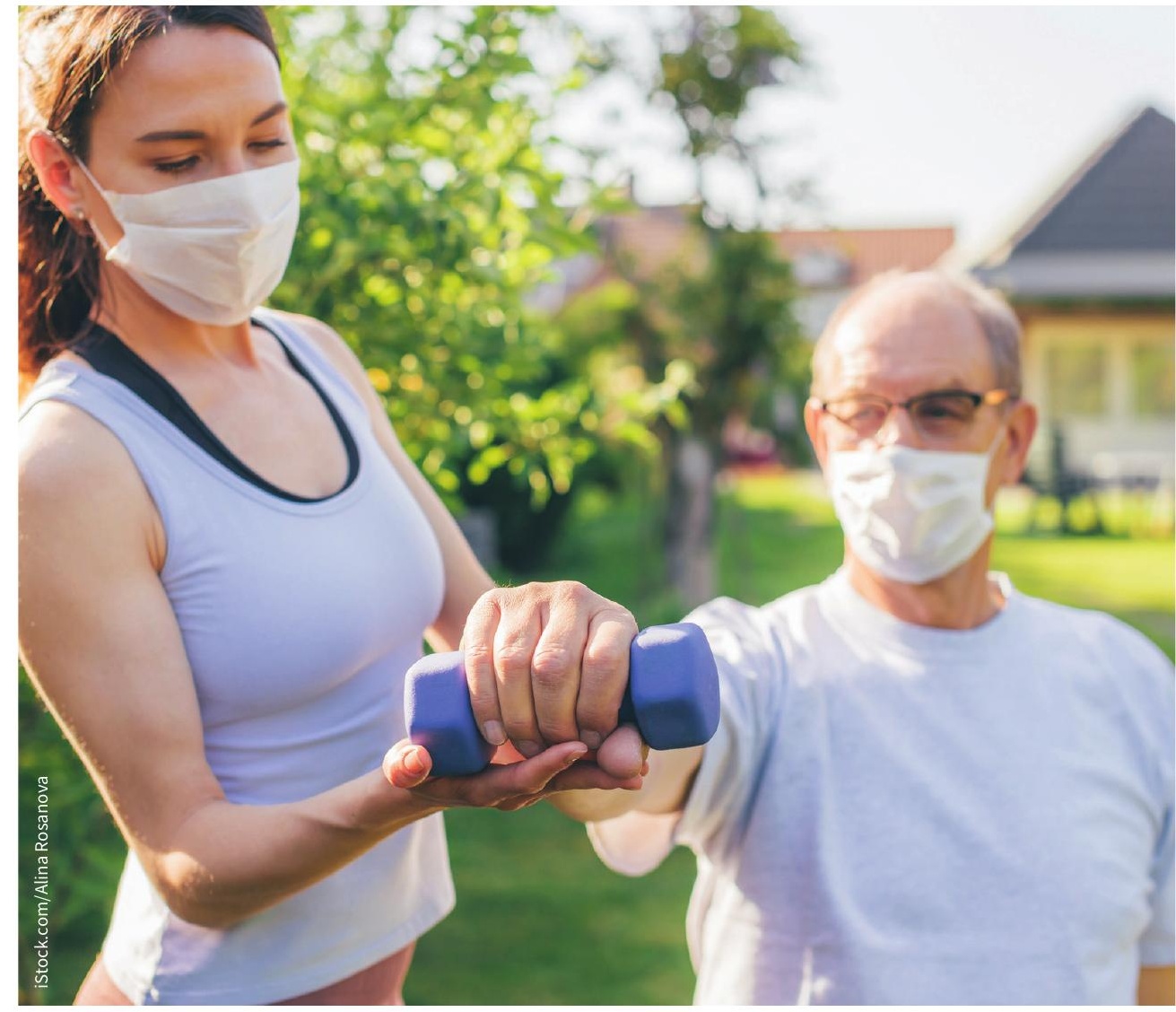

Patients may require months of rehabilitation after recovering from COVID-19.

with pulmonary rehabilitation, focusing on specific breathing techniques to use the body's oxygen more efficiently. Physical therapists providing these services may need to closely supervise patients and take extra precautions when working with patients with active infection.

According to Dr. Mark Bayley, medical program director at the Toronto Rehabilitation Institute, "there are a lot of moving parts here that we are still getting to understand."

Some patients recovering from COVID19 may require months of post-hospital care. At the same time, rehab facilities are still admitting their usual patients and accommodating patients who were discharged from hospitals to free up beds during the pandemic.

Preventing the spread of COVID-19 among these groups remains "the key challenge" for rehab facilities, says Bayley. The Toronto Rehabilitation Institute converted some programs to a virtual format, completing a transition in two weeks that Bayley says would typically take more than a year. The shift to online and telephone services 
reduced the risk of infection and freed some beds for patients from nearby hospitals. The centre also opened a 40-bed unit for people waiting for longterm care, and redeployed specialists who previously worked in outpatient programs to staff the unit.

In Calgary, Foothills Medical Centre's rehab unit moved to a decommissioned hospital to make space for patients with COVID-19. Grant says the move involved "mind-blowing logistical work," from putting in oxygen to setting up a pharmacy.
Meanwhile, on the west coast, Island Health in Victoria made a rapid transition to tele-rehab services. According to rehabilitation medical director Dr. Paul Winston, the shift to virtual services has improved access for patients and will likely continue after the pandemic. Previously, some patients had to book appointments around their access to transportation. For example, "if you want to book an accessible van, it's a two-week booking window," Winston explains.
However, tele-rehab also poses challenges. Winston notes that virtual consultations raise privacy concerns, and it can be difficult to assess patients from afar and create safe environments for exercise at home. Rehabilitation specialists across the country are working together to address these issues, he says. "A lot of change has happened very fast, and I think this has given people a lot of optimism that you can make systems changes in health care."

Allison Daniel, Toronto, Ont. 